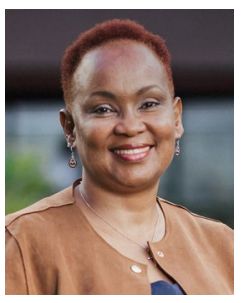

\title{
Expanding global access to genetic therapies
}

\author{
It is time to rethink intellectual property and pricing practices that prevent global access to \\ genetic therapies.
}

ast November marked the third anniversary of the announcement of the birth of twin girls resulting from the use of gene-editing in human embryos by Chinese scientist He Jiankui. Following this announcement, World Health Organization (WHO) Director General Tedros Adhanom Ghebreyesus established an 18-member Expert Advisory Committee on Developing Global Standards for Governance and Oversight of Human Genome Editing to examine the scientific, ethical, social and legal challenges associated with human genome editing. It was a great honor for me to serve on this committee, which resulted in a governance framework ${ }^{1}$, a position paper $^{2}$ and our recommendations ${ }^{3}$.

One of the goals of advancing science and technology should be to solve global health challenges by developing new therapies, treatments and preventative measures that could directly contribute to the enhancement of the collective well-being of societies. It was clear to the committee that human genome editing innovations should endeavor to do this, and any that did not, or that was potentially harmful, should not be allowed to continue. Today, technologies that should not be allowed at all include those attempting heritable germline human genome editing because of the risks and safety concerns surrounding current technology and also because of the new and possibly unique ethical challenges they would introduce.

Somatic gene editing therapies, by contrast, do not present the same risks and challenges, promising to provide treatments for a wide range of diseases and conditions, including cancers, blindness and hemophilia. To date, there are $\sim 156$ clinical trials registered in the WHO Human Genome Editing Registry.

Currently, the cost of human genome editing therapies ranges between $\$ 373,000$ and $\$ 2.1$ million $^{4}$. This high cost is partly due to the massive investments that biopharmaceutical companies make in research and development (R\&D), which are lengthy and expensive and carry the risk of a product not becoming a successful drug or therapy.
Patents are a part of this process. Without patents and other forms of intellectual property protection, few firms would risk investing in lengthy and expensive $R \& D$ projects without a guarantee that their investments would have a term of market exclusivity. However, it is all too common that the full implementation of patents, including awarding of a grace period for innovators to exclusively market their products, restrictive licensing terms, and the resulting lack of competition, drives up prices and limits patient access to treatments, even in wealthier countries.

The era of genetic therapies - both gene-editing treatments and gene therapies, several of which are now on the market has arrived for rare disease. But as more of these therapies come online, it is time to explore how current business models based on patents and restrictive licensing limit access to treatments. It is also time to explore whether there are other ways in which patents can still reward innovators and protect investments while ensuring that the widest number of patients who need these treatments can receive them.

One of the factors that drives up the cost of genetic therapies is that most monogenic human diseases are rare and thus only a small number of patients are amenable to treatment (some gene therapies target only 1,000-2,000 patients ${ }^{5}$ ). When future revenues for new drugs or therapies are projected to come from such a small number of patients, the final price of the therapy is high because a company expects a healthy return on investment. Until now, companies offering genetic therapies have prioritized patients living in developed countries because they have the personal financial resources or the availability of reimbursement mechanisms that can pay. The current high return on investment of the biotech business model provides the financial incentive to target orphan or rare disease markets. In contrast, few biotech companies target mass markets or price their products at prices suited to mass marketing; even fewer think about patients in developing countries. This situation contrasts starkly with the industry business model in the 1990s, where top-selling drugs had low price points and were marketed to large numbers of patients ${ }^{6}$ (the so-called blockbuster model).

As genetic therapies come online that target diseases that affect much larger groups of patients - for example, hemophilia (in $2019,1,125,000$ people living around the globe had the disease ${ }^{7}$ ), $\beta$-thalassemia (270 million heterozygous individuals worldwide ${ }^{8}$ in 2004) or sickle cell anemia (in 2010, 305,800 children were born worldwide with the condition ${ }^{9}$ ) - the biotech industry should consider revising its business model and pricing strategy so it is more in line with those of blockbusters. For common genetic conditions, prices should be lowered to account for the larger market size and to improve the accessibility of therapies to patients across the globe, particularly those in developing nations.

In the past decade, it has been possible to reduce the cost of antiretroviral (ARV) drugs from $\$ 12,000$ to less than $\$ 90$ per patient per year ${ }^{10}$ following stiff competition between generic drug manufacturers in developing countries, such as India. However, the real change was brought about by the concerted efforts of civil society, governments and international institutions working together to bring down prices. The resultant price drop has given ARV access to more than 5 million people in the developing world ${ }^{11}$.

It is reasonable to assume that a similar model can be applied to genetic therapy development for the developing world. We can expect generic gene therapy drug production to commence as soon as patents begin to expire, provided that Western manufacturers are willing to transfer the knowhow in vectorology, large-scale manufacture and product-quality assurance and control to manufacturers in the Global South. The current expansion of patent legislative framework into developing countries will facilitate the manufacture of generic gene therapies in the developing world, particularly if there is also a transfer of knowhow from pioneer companies. This, together with advances in manufacturing technologies to make genetic therapy production more efficient and cost-effective, can have a direct impact on pricing. 
Another strategy to reduce the cost of premium-priced gene therapies would be through the use of patent pools, which have been successfully applied in the technology and electronics world. Patent pools are agreements drawn up by two or three owners of different patents who transfer the intellectual property to a joint venture among themselves or with other third parties. The debate on the use of patent pools for gene therapy technology is not new ${ }^{12,13}$, including the negative effects on fair competition, product development and innovation. The legal challenges of developing such patent pools also cannot be ignored. However, the successful application of patent pools in the development of ARV drugs for use in developing countries has provided access to HIV treatments to thousands of patients who would otherwise not have been treated. Efforts to stop the COVID-19 pandemic have also led to new initiatives, such as the WHO-led COVID-19 Technology Access Pool, the goal of which is to facilitate access to COVID-19 health products while ensuring their affordability.

Such success stories should spur us to explore innovative ways to ensure that the successful genetic therapies under development will be broadly inclusive for patients, regardless of where they are located in the world.

\section{Anne W. T. Muigai}

School of Biological Sciences, Jomo Kenyatta University of Agriculture and Technology, Nairobi, Kenya.

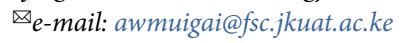

Published online: 7 January 2022

https://doi.org/10.1038/s41587-021-01191-0

References

1. WHO Expert Advisory Committee on Developing Global Standards for Governance and Oversight of Human Genome Editing. Human Genome Editing: A Framework for Governance (WHO, 2021); https://www.who.int/publications/i/item/ 9789240030060

2. WHO Expert Advisory Committee on Developing Global Standards for Governance and Oversight of Human Genome Editing. Human Genome Editing: Position Paper (WHO, 2021); https://www.who.int/publications/i/item/9789240030404
3. WHO Expert Advisory Committee on Developing Global Standards for Governance and Oversight of Human Genome Editing. Human Genome Editing: Recommendations (WHO, 2021); https://www.who.int/publications/i/item/ 9789240030381

4. Alhakamy, N. A., Curiel, D. T. \& Berkland, C. J. Drug Disc. Today 26, 1602-1619 (2021).

5. Spark Therapeutics. Spark Therapeutics announces first-of-their-kind programs to improve patient access to Luxturna (voretigene neparvovec-rzyl), a one-time gene therapy treatment. https://sparktx.com/press_releases/spark-therapeuticsannounces-first-of-their-kind-programs-to-improve-patientaccess-to-luxturna-voretigene-neparvovec-rzyl-a-one-time-genetherapy-treatment/ (2018)

6. Congressional Budget Office. Research and Development in the Pharmaceutical Industry (CBO, 2021); https://www.cbo.gov/ system/files/2021-04/57025-Rx-RnD.pdf

7. Iorio, A. et al. Ann. Intern. Med. 171, 540-547 (2019).

8. Weatherall, D. J. Nature Rev. Genet. 5, 625-631 (2004).

9. Piel, F. B., Hay, S. I., Gupta, S., Weatherall, D. J. \& Williams, T. N. PLoS Med. 10, e1001484 (2013).

10. Médecins Sans Frontières. Untangling the Web of Antiretroviral Prices $11^{\text {th }}$ Edition (Médecins Sans Frontières, 2008); https://msfaccess.org/untangling-web-hiv-medicine-pricingaccess-issues-2020

11. Joint United Nations Programme on HIV/AIDS (UNAIDS). UNAIDS Outlook Report (WHO, 2010).

12. Horn, L. Science 355, 1274 (2017)

13. Contreras, J. L. \& Sherkow, J. S. Science 355, 1274-1275 (2017).

Competing interests

The author declares no competing interests. 